\title{
Identification of a differentially expressed gene, $A C L$, between Meishan $\times$ Large White and Large White $\times$ Meishan F1 hybrids and their parents
}

\author{
Zhu-Qing Ren, Yan Wang, Yong-Jie Xu, Lin-Jie Wang, \\ Ming-Gang Lei, Bo Zuo, Feng-E Li, De-Quan Xu, Rong Zheng, \\ Chang-Yan Deng, Si-Wen JiAng, Yuan-Zhua Xiong*
}

Key Laboratory of Swine Genetics and Breeding of Ministry of Agriculture \& Key Laboratory of Agriculture Animal Genetics, Breeding and Reproduction of Ministry of Education, College of Animal Science, Huazhong Agricultural University, Wuhan 430070, China

(Received 23 January 2008; accepted 26 June 2008)

\begin{abstract}
ATP-citrate lyase (ACL), one of the lipogenic enzymes, catalyses the formation of acetyl-coenzyme A (CoA) involved in the synthesis of fatty acid and cholesterol. In pig, very little is known about the $A C L$ gene. In this work, the mRNA differential display technique was used to analyse the differences in gene expression between Meishan and Large White pigs and the F1 hybrids of both direct and reciprocal crosses. Our results show that among the differentially expressed genes $A C L$ is up-regulated in the backfat of the F1 hybrids. After cloning and analysing the fulllength cDNA and the $870 \mathrm{bp} 5^{\prime}$-flanking sequence of the porcine $A C L$ gene, a $C / T$ mutation at position -97 bp upstream of the transcription site was detected. Luciferase activity detection showed that this mutation changed the transcriptional activity. In F1 hybrids, the heterozygous genotype $C T$ was more frequent than the homozygous genotypes $C C$ and TT. Real-time PCR analysis showed that in Meishan pigs, $A C L$ mRNA expression was more abundant in individuals with genotype $C T$ than in those with genotype $C C$ or $T T$ or in Large White pigs. These results indicate that the $C / T$ mutation affects $A C L$ mRNA expression, probably via the activator protein 2 .
\end{abstract}

differential gene expression / ATP-citrate lyase / promoter / mutation / pigs

\section{INTRODUCTION}

Significant phenotypic differences exist between Chinese indigenous Meishan pigs and western commercial Large White pigs. The latter present higher growth rate, carcass lean meat percentage and feed to body weight conversion ratio,

*Corresponding author: xiongyuanzhua@163.com 
whereas Chinese indigenous pigs have higher prolificacy, superior meat quality and strong resistibility. Offspring produced by crossbreeding distantly related breeds frequently display greater vigour, size, resistance, etc., than the respective parents. Since phenotypic variances mainly result from genotypic differences, it is necessary to provide experimental evidence for the genetic basis to differences between hybrids and their parents. In our laboratory, using suppression subtractive hybridization (SSH) and mRNA differential display, we have detected significant differences in mRNA quantities and expression patterns for several genes between porcine F1 hybrids and their parents [12,17,19]. Thus, cloning and characterizing genes that are differentially expressed between hybrids and their parents should provide further insights into the genetic basis of phenotypic differences. In this work, we show that, in backfat, the gene ATP-citrate lyase $(A C L)$ is differentially expressed between Meishan $\times$ Large White and Large White $\times$ Meishan F1 hybrids and their parents.

$\mathrm{ACL}$ is a cytosolic enzyme that catalyses the formation of acetyl-coenzyme A $(\mathrm{CoA})$ and oxaloacetate from citrate and CoA, with the hydrolysis of ATP to ADP and phosphate [7]. Since the acetyl-CoA produced by ACL is involved in the synthesis of fatty acid and cholesterol, ACL is considered as one of the lipogenic enzymes like fatty acid synthase and acetyl CoA carboxylase [3]. In mammals, the activity of ACL is regulated by diet regimen and insulin [6]. It is generally believed that changes in ACL activity in terms of the de novo lipogenesis state are due to alterations in the rate of its biosynthesis [4]. In rat, it has been shown that changes in ACL activity correlate with modifications of its mRNA concentration and transcription rate, and that $A C L$ mRNA amounts begin to decrease when the level of hepatic lipogenesis is low [5]. Other studies have reported that $A C L$ expression in liver is regulated at the transcriptional level by SREBP-1 [18] and that lipid biosynthesis rates and $A C L$ mRNA expression increase when fasted mice are fed a carbohydrate-rich diet [16]. These findings strongly suggest that ACL activity is regulated at the transcription level. However, very little is known about $A C L$ and its expression pattern in pig. In this paper, we describe the cloning and expression profile of the porcine $A C L$ gene. In addition, we present the characterization of its transcriptional activity and the detection of a mutation in its promoter region that alters transcriptional activity.

\section{MATERIALS AND METHODS}

\subsection{Animals}

Fifty-eight Large White pigs, 33 Meishan pigs, 81 Large White $\times$ Meishan pigs and 48 Meishan $\times$ Large White pigs maintained at the Huazhong Agricultural 
University Jingpin Pig Station were fed the same diet and sampled at the age of six months.

\subsection{Differential display of mRNA}

Three boars and three sows for each Meishan $\times$ Large White and Large White $\times$ Meishan hybrid and their parents i.e. a total of 24 pigs were sampled. Total RNA was isolated from the backfat of these 24 pigs and for each breed and each hybrid, the RNA from six individuals was pooled into one tube, respectively. Total RNA samples were treated with DNase I (Promega, USA) to eliminate any contaminating genomic DNA. Subsequently, cDNA sequences were synthesized with M-MLV reverse transcriptase and an oligo (dT)15 anchored primer (Promega, USA). Differential display PCR was carried out as described by Ren et al. [17]. After differential display, cDNA fragments were re-amplified, cloned and sequenced. The sequences were compared with those available in GenBank using BLAST.

\subsection{Reverse transcription PCR analysis}

Semi-quantitative RT-PCR was used to evaluate $A C L$ expression in the backfat of F1 hybrids and their parents. The primer pair, GHF and GHR, was synthesized to amplify specifically the housekeeping gene, glyceraldeyhyde3-phosphate dehydrogenase $(G A P D H)$, as an internal control (all primer sequences used in this study are presented in Tab. I). The differentially expressed cDNA fragment, EST39, was detected with the gene-specific primers EST39F and EST39R. GAPDH and EST39 were amplified in separate tubes and electrophoresed on $1.5 \%$ agarose/ethidium bromide gels. Densitometry values were measured using the BandScan software (www.Glyko.com). RT-PCR values are presented as ratios between the EST39 signal in the selected exponential amplification cycle and the GAPDH signal. Each sample was amplified eight times. In addition, semi-quantitative RT-PCR was used to identify porcine sp1, SREBP-1 and SREBP-2 expression in backfat of F1 hybrids and their parents.

\subsection{Cloning of the $A C L$ cDNA and its 5 '-flanking sequence}

Switching Mechanism At 5' end of the RNA Transcript (SMART) cDNA was synthesized using the SMART PCR cDNA Synthesis Kit (Clontech, USA) for RACE-PCR. The $5^{\prime}$ and $3^{\prime}$ ends of $A C L$ cDNA were obtained with primer pairs Smart5 $5^{\prime} / \mathrm{GSP} 1$ and $\mathrm{Smart}^{\prime} / \mathrm{GSP} 2$, respectively. 
Table I. Primers used in the present study.

\begin{tabular}{|c|c|c|c|}
\hline Primers & $\begin{array}{l}\text { Sequences } \\
\text { (from } 5^{\prime} \text { to } 3^{\prime} \text { ) }\end{array}$ & $\begin{array}{c}\text { Annealing } \\
\text { temperature }\left({ }^{\circ} \mathrm{C}\right)\end{array}$ & $\begin{array}{c}\text { Gene } \\
\text { amplified }\end{array}$ \\
\hline GHF & ACCACAAGTCCATGCCATCAC & 58 & GAPDH \\
\hline GHR & TCCACCACCCTGTTGCTGTA & & \\
\hline EST39F & CCCTTTGCCATTGTTATA & 57 & EST39 \\
\hline EST39R & TCAGAGGTCGGTCAAACG & & \\
\hline sp1F & ACGGGCAATACCCTCTGG & 55 & spl \\
\hline sp1R & AGGACTCGTCGGGAAGCA & & \\
\hline SREBP-1F & CCACCAGTCCTGATGCCA & 54 & $S R E B P-1$ \\
\hline SREBP-1R & AGCCTTCAAGCGGGGAG & & \\
\hline SREBP-2F & CAAGCTCTTGAAAGGCATCG & 58 & $S R E B P-2$ \\
\hline SREBP-2R & AGAGGGCTTCCTGGCTCA & & \\
\hline Smart5' & AACGCAGAGTACGCGGG & 57 & $A C L$ \\
\hline GSP1 & CAGCCAAGGGTGGTCCTGC & & \\
\hline Smart3' & CAGAGTACTTTTTTTTTTTTTTTT & 57 & $A C L$ \\
\hline GSP2 & AGCAGGGGCTGTATCGTC & & \\
\hline R1 & NGTCGASWGANAWGAA & & \\
\hline R2 & GTNCGASWCANAWGTT & & \\
\hline R3 & WGTGNAGWANCANAGA & & \\
\hline R4 & NCAGCTWSCTNTSCTT & & \\
\hline ACSE & СTGCTCTCTACGAAAGGCCGTGC & & \\
\hline ACSF & CCCAACTCGCCGCCTACCTTCC & & \\
\hline ACSG & TCGCCGCCTACCTTCCGGAGCGC & & \\
\hline RGHF & ACCACAAGTCCATGCCATCAC & 58 & GAPDH \\
\hline RHGR & TCCACCACCCTGTTGCTGTA & & \\
\hline RACLF & TCTGGGAGGTGTCAACGAG & 58 & $A C L$ \\
\hline RACLR & GGTCTTGGCATAGTCATAGGT & & \\
\hline AC996F & GCTACGCGTTCAGCACTATCAGATCGGG & & \\
\hline AC756F & GCTACGCGTCCTTCCTAGCCCCACCT & & \\
\hline AC698F & GCCACGCGTATCTATTAGCCTCGTCCCAC & & \\
\hline AC486F & GATACGCGTCAGCCCGCCACATCTCAG & & \\
\hline $\mathrm{AC} 374 \mathrm{~F}$ & GATACGCGCATAGCCCAGCCCATCTC & & \\
\hline $\mathrm{AC} 216 \mathrm{~F}$ & GATACGGCGAATTGGGAGGAAGCC & & \\
\hline $\mathrm{AC} 169 \mathrm{~F}$ & GATACGCAATCGCCGGGCGGCTCGC & & \\
\hline $\mathrm{AC} 158 \mathrm{~F}$ & GATACGCGGCTCGCACGGTGTGCC & & \\
\hline ACR & GTACTCGAGCTGCTCTCTACGAAAGGCC & & \\
\hline
\end{tabular}

The $5^{\prime}$-flanking sequence of the $A C L$ gene was amplified by genome walking based on Thermal Asymmetric Interlaced PCR (TAIL-PCR) [11]. R1, R2, R3 and R4 were used as arbitrary primers and ACSE, ACSF and ACSG as genespecific primers. All PCR products were cloned into pMD-18T vector (Takara, Japan) and sequenced commercially. 


\subsection{Mutation detection and genotyping}

The $5^{\prime}$-flanking region of the $A C L$ gene was amplified by PCR from genomic DNA of three Meishan and three Large White pigs with primer pairs AC996F and ACR, and sequenced to identify novel mutations. Allele frequencies were then determined in the different pig populations.

\subsection{SYBR Green RT-PCR analysis of $A C L$ expression}

Relative quantitative RT-PCR was performed as follows: denaturation at $95{ }^{\circ} \mathrm{C}$ for $2 \mathrm{~min}$ followed by 45 cycles of $95{ }^{\circ} \mathrm{C}$ for $30 \mathrm{~s}, 58{ }^{\circ} \mathrm{C}$ for $30 \mathrm{~s}$ and $72{ }^{\circ} \mathrm{C}$ for $18 \mathrm{~s}$ (ABI, USA). Porcine $G A P D H$ and $A C L$ genes were amplified with primers RGHF/RGHR and RACLF/RACLR, respectively.

For spatial expression analysis, total RNA was also isolated from various Meishan pig tissues including backfat tissue, Longissimus dorsi, heart, liver, spleen, lung, kidney, stomach, uterus, ovary and small intestine. Each sample was repeated four times and the comparative $C_{\mathrm{t}}\left(\Delta \Delta C_{\mathrm{t}}\right)$ value method [13] was used to compute relative quantifications. Expression levels were considered as undetectable when the $C_{\mathrm{t}}$ value of the targeted gene exceeded 35 in the sample tissue.

\subsection{Plasmid construction}

A 1014 bp DNA fragment was amplified by PCR from porcine genomic DNA with primers AC996F and ACR as sense and anti-sense oligonucleotides, respectively. Mlu $I$ and Xho $I$ restriction sites were introduced in the $5^{\prime}$ ends of AC996F and ACR, respectively. The PCR product was double-digested by Mlu I and Xho I. The Mlu I/Xho I (-853/143 bp) fragment was subcloned into the pGL3-Basic vector (Promega, USA) to yield construct $-853 \mathrm{bp}$. Constructs $-613,-555,-343,-231,-73,-27$ and -15 bp were also produced using the forward primers AC756F, AC698F, AC486F, AC374F, AC216F, AC169F and $\mathrm{AC} 158 \mathrm{~F}$ in combination with the reverse primer ACR, respectively. The constructs were identified by double-digestion and sequencing. This method refers to Butta et al. [1].

\subsection{Cell culture, transient transfection and luciferase assay}

Pig kidney cells (PK-15) purchased from China Center for Type Culture Collection were cultured in Dulbecco's modified Eagle's medium, supplemented with $10 \%(\mathrm{v} / \mathrm{v})$ bovine calf serum (Gibco, USA) and maintained at $37^{\circ} \mathrm{C}$ in $5 \% \mathrm{CO}_{2}$. 
Cells were seeded into 24 -well plates at an initial density of $60-80 \%$ and cultured overnight to ensure adhesion and spreading. Co-transfections were then performed using $2 \mu \mathrm{L}$ of Lipofectamine 2000 reagent (Invitrogen) with $3 \mu \mathrm{g}$ of the firefly luciferase plasmid DNA, and $0.6 \mu \mathrm{g}$ of pRL-TK plasmid DNA (Promega, USA) as an internal control. For co-transfection analyses, the levels of reporter plasmids were kept constant. The pGL3-Control vector (Promega, USA) was used as a positive control. After $6 \mathrm{~h}$, the transfection medium was removed and replaced with growth medium.

Transfected cells were collected by rocking the plates for 15 min with $1 \mathrm{X}$ passive lysis buffer (PLB, Promega, USA). Firefly and Renilla luciferase activities were measured at $48 \mathrm{~h}$ post-transfection using the Dual-Glo Luciferase Assay System (Promega, USA) and a TD20/20 luminometer (Turner Designs). In each case, transfection efficiencies were normalized using the Renilla luciferase activity levels and each construct was tested in triplicate in a minimum of three independent experiments. In addition, a $t$-test was performed to compare the transcriptional activities between these recombinants.

\section{RESULTS}

\subsection{Identification of EST39, an up-regulated gene, in F1 hybrids}

One band, designated as EST39 and visualized only in the Large White $\times$ Meishan and Meishan $\times$ Large White F1 hybrids, was isolated from the differential display gel (Fig. 1A) and re-amplified. Semi-quantitative RT-PCR analysis showed that the expression level of EST39 in backfat was higher in the F1 hybrids than in their parents (Fig. 1B).

\subsection{Cloning and analysis of porcine $A C L$ gene}

The differentially expressed EST39 shares $88 \%$ sequence identity with the human $A C L$ gene. A 3463 bp contig was constructed by in silico cloning using the GenBank ESTs database. We obtained a 4378 bp full-length porcine $A C L$ cDNA (GenBank Accession No. EU073662) by $5^{\prime}$ and $3^{\prime}$ RACE-PCR. Porcine $A C L$ gene contains a 3231 nucleotide (nt) open reading frame. We inferred that the ATG codon at nt residue 134-136 is the true start site of translation, because it begins the longest reading frame and is preceded by one in-frame stop codon in the $5^{\prime}$ untranslated region [8].

Analysis of a $870 \mathrm{bp}$ sequence in the $5^{\prime}$-flanking region (GenBank Accession No. EU073663) of the porcine $A C L$ gene obtained by TAIL-PCR showed no TATA-like elements but a high $\mathrm{G}+\mathrm{C}$ content in the proximal promoter region. Potential binding sites for the transcription factors were predicted using 


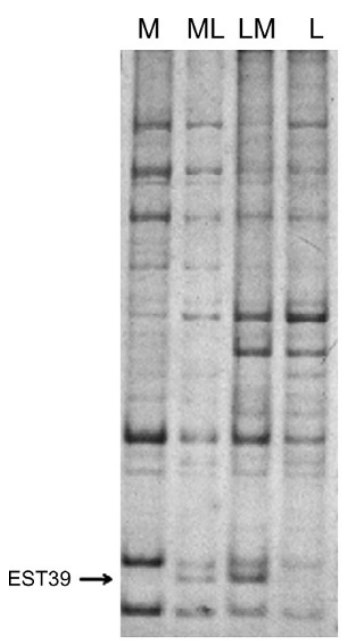

A
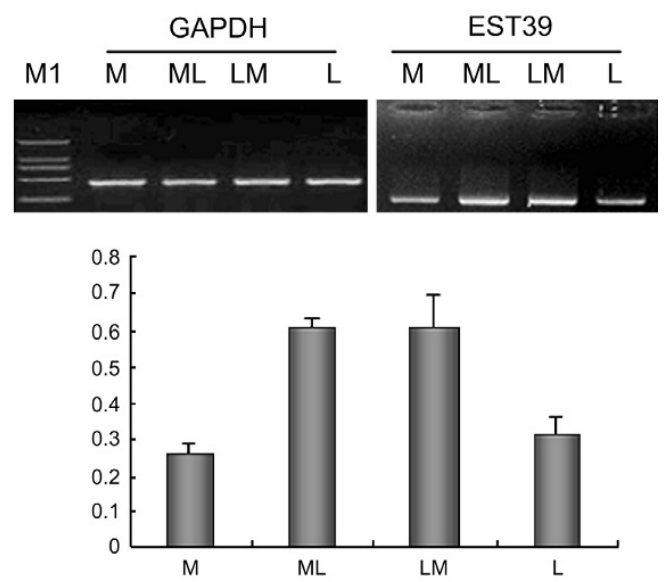

B

Figure 1. Identification of EST39 an up-regulated gene in the backfat of F1 hybrids as compared with their parents. (A) Silver staining of mRNA differential display. The arrow points to EST39. M, ML, LM and L represent Meishan, Meishan $\times$ Large White, Large White $\times$ Meishan and Large White pigs, respectively. (B) Semiquantitative RT-PCR analysis of EST39 and the bar graph of the percentage of EST39/GAPDH.

the software "Searching Transcription Factor Binding Sites" with an 85 threshold score (TFSEARCH program, Version 1.3). The following transcription factors were investigated: stimulating protein 1 (sp1), GATA (GATA-binding factor) family, heat shock factor, upstream stimulating factor, cap (cap signal for transcription initiation), activator protein 4 (AP-4) and activator protein 2 (AP-2).

\subsection{Xho I PCR-RFLP polymorphism in the $5^{\prime}$-flanking region of porcine $A C L$ gene}

A $C / T$ mutation was found at position $-97 \mathrm{bp}$ from the transcription site. The forward (5'-CGCCTTCCTAGCCCCACCT- $\left.3^{\prime}\right)$ and reverse (5'-CGCCGCCTACCT-TCCGGAG-3') primers amplify a 711 bp product. The $A C L$ C-97T introduces a Xho $I$ recognition site in the presence of $T$, resulting in the digestion of the $711 \mathrm{bp}$ fragment into two $518 \mathrm{bp}$ and $193 \mathrm{bp}$ fragments, consequently forming three genotypes $C C, C T$ and $T T$. In addition, the transition from $C$ to $T$ results in the absence of a binding site for AP-2 as predicted by TFSEARCH.

We have genotyped 58 Large White, 33 Meishan, 81 Large White $\times$ Meishan and 48 Meishan $\times$ Large White pigs for the Xho I PCR-RFLP polymorphism 
Table II. Genotype and allele frequencies in F1 hybrids and their parents.

\begin{tabular}{|c|c|c|c|c|c|c|}
\hline \multirow[t]{2}{*}{ Breed } & \multirow[t]{2}{*}{ Number } & \multicolumn{3}{|c|}{ Genotype frequency } & \multicolumn{2}{|c|}{$\begin{array}{c}\text { Allele } \\
\text { frequency }\end{array}$} \\
\hline & & $C C$ & $C T$ & $T T$ & $C$ & $T$ \\
\hline Large White & 58 & 0.776 & 0.224 & 0.000 & 0.888 & 0.112 \\
\hline Meishan & 33 & 0.182 & 0.667 & 0.152 & 0.515 & 0.485 \\
\hline Large White $\times$ Meishan & 81 & 0.346 & 0.568 & 0.086 & 0.630 & 0.270 \\
\hline Meishan $\times$ Large White & 48 & 0.292 & 0.521 & 0.188 & 0.522 & 0.478 \\
\hline
\end{tabular}

and calculated genotype and allele frequencies (Tab. II). No genotype $T T$ was detected in Large White pigs. Among the four pig populations, allele $C$ was more frequent than allele $T$. The homozygous genotype $C C$ was preponderant in Large White pigs, whereas genotype $C T$ was the most frequent genotype in Meishan pigs and F1 hybrids.

\subsection{Expression profile of porcine $A C L$}

Real-time analysis was performed to further reveal the differential expression of $A C L$ between $\mathrm{F} 1$ hybrids and their parents. GAPDH was used to normalize the expression level of $A C L$. The relative quantitative results showed that $A C L$ mRNA in backfat was up-regulated in $\mathrm{F} 1$ hybrids in comparison with their parents (Fig. 2A).

To isolate total RNA from backfat, we selected six Meishan and Large White pigs with genotypes $C C, C T$ and $T T$, respectively (no genotype $T T$ was detected in Large White pigs). RT-PCR results showed that $A C L$ mRNA expression was more abundant in Meishan pigs with genotype $C T$ than in those with genotype $C C$ or $T T$ or in Large White pigs (Fig. 2B).

We have also determined the spatial expression of $A C L$ in various porcine tissues (Fig. 2C). The highest level of porcine $A C L$ mRNA expression was observed in the uterus, followed by the ovary, small intestine, lung, spleen, liver, kidney, backfat and stomach, whereas expression in skeletal and cardiac muscles was weak.

In addition, we analysed the mRNA expression of porcine $s p 1, S R E B P-1$ and SREBP-2 genes in backfat and the results showed no significant difference between F1 hybrids and their parents (Fig. 3).

\subsection{Features of the $5^{\prime}$-flanking region of porcine $A C L$ gene}

To identify the location of the promoter region in the porcine $A C L$ gene, we have studied the transcriptional activity of recombinants with progressively 

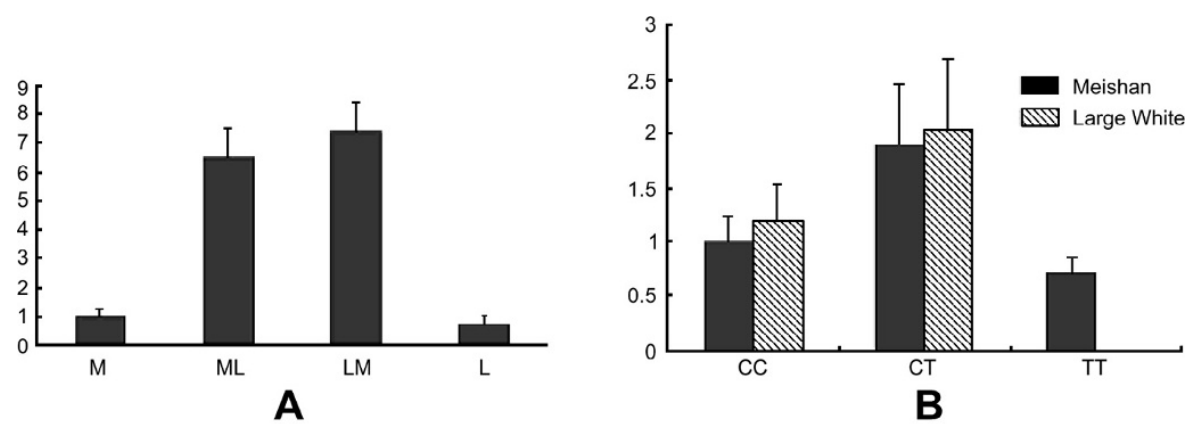

B

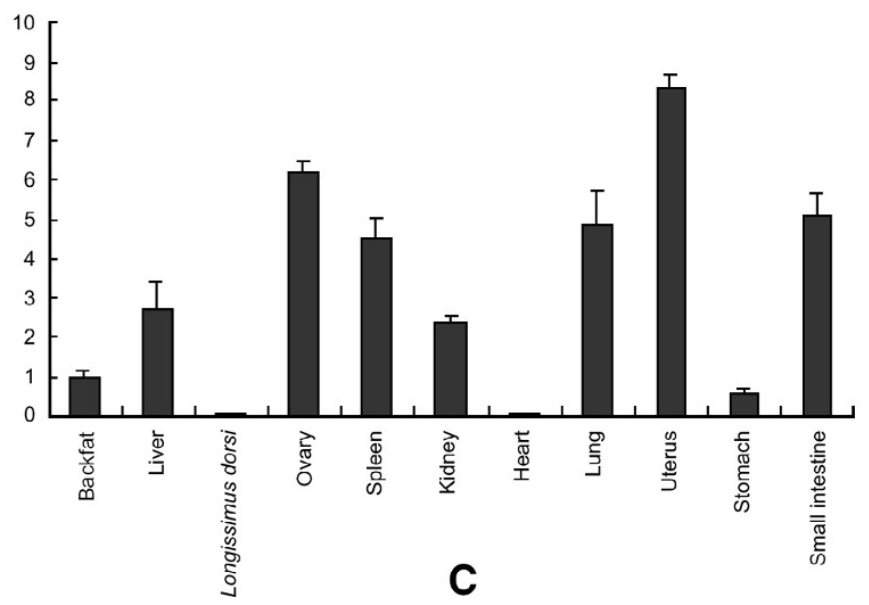

Figure 2. mRNA expression of three isoforms of porcine $A C L$ by RT-PCR. Error bars indicate the SD $(n=4)$ of relative $A C L$ mRNA expression levels to $G A P D H$, determined by RT quantitative PCR. The values were normalized to the housekeeping gene $G A P D H$ expression. (A) Porcine $A C L$ mRNA expression in backfat between $\mathrm{F} 1$ hybrids and their parents. The value of $A C L$ in Meishan pigs was arbitrarily set to 1 . (B) Porcine $A C L$ mRNA expression in Meishan and Large White pigs with genotypes $C C, C T$ and $T T$. The value of $A C L$ in Meishan pigs with genotype $C C$ was arbitrarily set to 1. (C) The tissue distribution of porcine $A C L$ including backfat, liver, L. dorsi, ovary, spleen, kidney, heart, lung, stomach, small intestine and uterus. The value of $A C L$ in backfat was arbitrarily set to 1 .

5 -deleted DNA fragments (from $-853,-613,-555,-343,-231,-73,-27$, -15 to $+143 \mathrm{bp}$, respectively) subcloned into the pGL3-Basic reporter plasmid (Fig. 4A). Recombinants, carrying a $\mathrm{C}$ at position $-97 \mathrm{bp}$ instead of a $\mathrm{T}$, were transiently transfected into PK-15 cells. Detection of the luciferase relative activity showed that transcriptional activity was not significantly different between recombinants $-15,-27$ and pGL3-Basic. Activity was detected from construct 


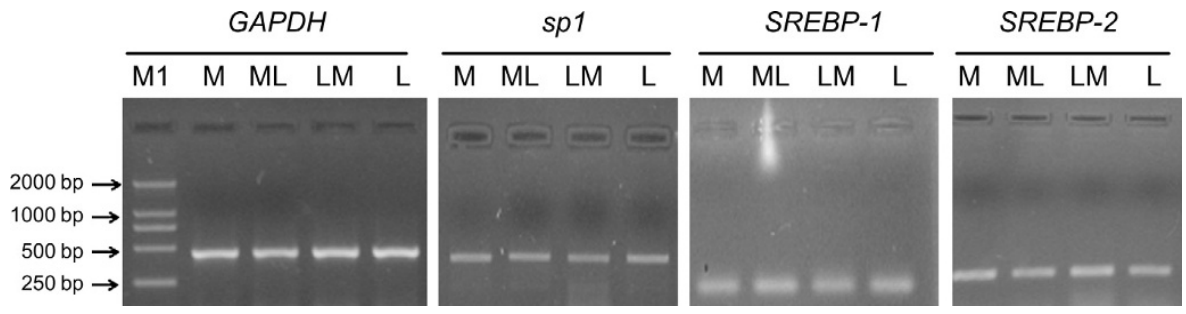

Figure 3. RT-PCR analysis of $s p 1, S R E B P-1$ and $S R E B P-2$ genes. M1 corresponds to the DNA molecular size marker and M, ML, LM and L to Meishan, Meishan $\times$ Large White, Large White $\times$ Meishan and Large White pigs, respectively.

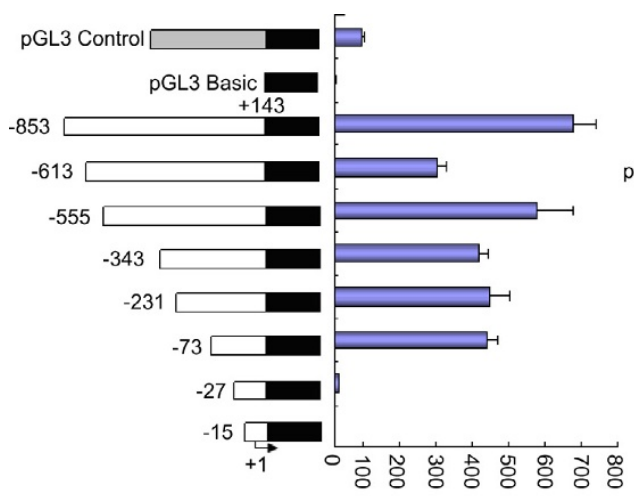

A

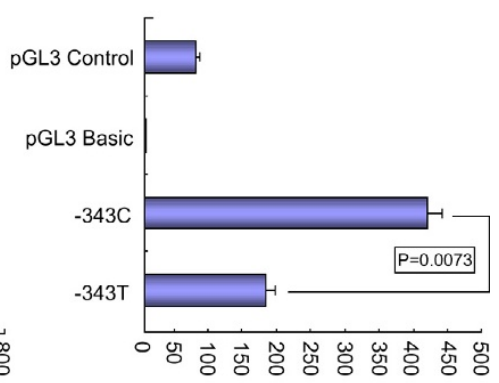

B

Figure 4. Transient transfection of deletion mutants of the $5^{\prime}$-flanking region of the porcine $A C L$ gene. Luciferase activity was corrected for transfection efficiency with the values obtained with Renilla. The results are means \pm SD of three experiments performed in duplicate. (A) Transcriptional activity of eight recombinants. (B) Comparison of luciferase activity between constructs $-343 \mathrm{C}$ and $-343 \mathrm{~T}$.

-73 and increased in constructs from $-73 \mathrm{bp}$ to $-853 \mathrm{bp}$ with a little fluctuation. Thus, these experiments show that the basal promoter activity is located within the $-73 \mathrm{bp}$ to $+143 \mathrm{bp}$ region, while the region from $-853 \mathrm{bp}$ to $+143 \mathrm{bp}$ confers maximal transcriptional activity.

To investigate whether the $C / T$ mutation alters transcriptional activity, we constructed recombinants $-343 \mathrm{C}$ and $-343 \mathrm{~T}$, corresponding to alleles $C$ and $T$. Results from transient transfection experiments showed that the transcriptional activity of construct $-343 \mathrm{~T}$ was significantly lower than that of construct $-343 \mathrm{C}(P<0.01)$ (Fig. 4B). 


\section{DISCUSSION}

Many methods have been used to reveal differential gene expression, such as SSH, cDNA-RDA (cDNA representational differential analysis), SAGE (serial analysis of gene expression) and DNA microarray. Compared with these methods, the advantage of the mRNA differential display technique is that more than two samples can be displayed simultaneously, as shown in our experiments. However, its shortcoming is that it gives a high percentage of false positives and thus, the differentially expressed ESTs displayed in a gel need further identification. In the present study, we have isolated a cDNA fragment (EST39) that is present in the backfat of F1 hybrids but not in the parents. Subsequently, we have confirmed mRNA differential expression of EST39 between F1 hybrids and their parents by both semi-quantitative and RT-PCRs.

Both porcine and rat $A C L$ mRNAs are expressed in most tissues [2]. In fact, in human, rat and pig the promoter region of the $A C L$ gene has no TATA box, which is usually a feature of housekeeping genes. However using RT-PCR, we have shown that the porcine $A C L$ gene is differentially expressed between the F1 hybrids and their parents. Thus, our results suggest that upstream transcription factors or other proteins regulate this differential expression. It has been found that $\mathrm{sp} 1$ is one of the most important transcription factors for the $A C L$ promoter to produce basal and induced transcription by low fat/high carbohydrate diet [15]. Sterol regulatory element-binding proteins (SREBPs), especially SREBP-1, regulate ACL enzyme activity at the transcriptional level, whereas NF-Y binding is a prerequisite for activating the $A C L$ promoter [14]. Diet and various hormones also regulate ACL activity $[5,6]$. In rats, the concentration of ACL enzyme is increased 20- to 39-fold when they are subjected to fasting and then re-feeding. The promoter sequence of porcine $A C L$ gene is highly conserved with those of rat and human, suggesting that regulation at the transcription level is similar in these three species. Based on the above findings, we have analysed the mRNA expression of porcine $s p 1, S R E B P-1$ and SREBP-2 genes between $\mathrm{F} 1$ hybrids and their parents and have found no significant difference. Thus, other mechanisms are responsible for the differential expression. BLAST analysis between the $A C L$ promoter sequence from Meishan pigs and Large White pigs detected a $C / T$ mutation at position $-97 \mathrm{bp}$. A transition from $\mathrm{C}$ to $\mathrm{T}$ in the promoter region is predicted to result in the absence of a binding site to AP-2. Thus, we have constructed recombinant plasmids $-343 \mathrm{C}$ and $-343 \mathrm{~T}$, corresponding to $-97 \mathrm{C}$ and $\mathrm{T}$, and the results have shown that the former has a significantly higher transcriptional activity $(P<0.01)$. A similar effect has been reported for other genes. Kroeger [9] has reported that in PMAstimulated Jurkat and U937 cells, the $-308 \mathrm{~A}$ allelic form of the tumour 
necrosis factor-alpha gene increases two-fold the transcription level as compared with the $-308 \mathrm{G}$ form. Furthermore, in the $C D 14$ promoter, a $\mathrm{C} / \mathrm{T}$ transition at position -159 increases the transcriptional activity and decreases the affinity of Sp1 protein binding [10]. Thus, in the $A C L$ promoter, a $\mathrm{C} / \mathrm{T}$ transition at position -97 probably decreases the affinity of AP-2 protein binding and depresses the transcriptional activity. Accordingly, the transcriptional activity of porcine $A C L$ promoter in heterozygotes $C T$ or homozygotes $C C$ should be higher than in homozygotes $T T$ regardless of a dominant or additive effect. In addition, our results show that $A C L$ mRNA expression is more abundant in Meishan pigs with the genotype $C T$ than in those with genotype $C C$ or $T T$ or in Large White pigs. Thus, we speculate that the transcriptional activity of the porcine $A C L$ promoter in heterozygotes $C T$ is higher than in homozygotes $C C$ or $T T$, which should help to understand the genetic basis of the differences between F1 hybrids and their parents.

\section{ACKNOWLEDGEMENTS}

We thank the staff at Huazhong Agriculture University Jingpin Pig Station and teachers and students at Agriculture Ministry Key Laboratory of Swine Genetics and Breeding. This work was funded by the National Key Foundation Research and Development Program of China (2006CB102102), Specialpurpose Fund for Agricultural Profession (nyhyzx07-034) and International Foundation for Science (B/4534-1).

\section{REFERENCES}

[1] Butta N., Larrucea S., Alonso S., Rodriguez R.B., Arias-Salgado E.G., Ayuso M.S., González-Manchón C., Parrilla R., Role of transcription factor Sp1 and $\mathrm{CpG}$ methylation on the regulation of the human podocalyxin gene promoter, BMC Mol. Biol. 7 (2006) 17.

[2] Elshourbagy N.A., Near J.C., Kmetz P.J., Sathe G.M., Southan C., Strickler J.E., Gross M., Young J.F., Wells T.N., Groot P.H., Rat ATP citrate-lyase: molecular cloning and sequence analysis of a full-length cDNA and mRNA abundance as a function of diet, organ, and age, J. Biol. Chem. 265 (1990) 1430-1435.

[3] Gibson D.M., Lyons R.T., Scott D.F., Muto Y., Synthesis and degradation of the lipogenic enzymes of rat liver, Adv. Enzyme Regul. 10 (1972) 187-204.

[4] Katsurada A., Fukuda H., Iritani N., Effects of dietary nutrients on substrate and effector levels of lipogenic enzymes, and lipogenesis from tritiated water in rat liver, Biochim. Biophys. Acta 878 (1986) 200-208.

[5] Kim K.S., Park S.W., Kim Y.S., Regulation of ATP-citrate lyase at transcriptional and post-transcriptional levels in rat liver, Biochem. Biophys. Res. Commun. 189 (1992) 264-271. 
[6] Kim K.S., Kang J.G., Moon Y.A., Park S.W., Kim Y.S., Regulation of ATP-citrate lyase gene transcription, Yonsei Med. J. 37 (1996) 214-224.

[7] Kornacker M.S., Ball E.G., Citrate cleavage in adipose tissue, Proc. Natl. Acad. Sci. USA 54 (1965) 899-904.

[8] Kozak M., An analysis of $5^{\prime}$ non-coding sequences from 699 vertebrate messenger RNAs, Nucleic Acids Res. 15 (1987) 8125-8128.

[9] Kroeger K.M., Carville K.S., Abraham L.J., The -308 tumor necrosis factoralpha promoter polymorphism effects transcription, Mol. Immunol. 34 (1997) 391-399.

[10] LeVan T.D., Bloom J.W., Bailey T.J., Karp C.L., Halonen M., Martinez F.D., Vercelli D., A common single nucleotide polymorphism in the CD14 promoter decreases the affinity of Sp protein binding and enhances transcriptional activity, J. Immunol. 167 (2001) 5838-5844.

[11] Liu Y.G., Whittier R.F., Thermal asymmetric interlaced PCR: automatable amplification and sequencing of insert end fragments from P1 and YAC clones for chromosome walking, Genomics 25 (1995) 674-681.

[12] Liu G.Y., Xiong Y.Z., Deng C.Y., Zuo B., Zhang J.H., Comparison of gene expression patterns in Longissimus dorsi of pigs between the high-parent heterosis cross combination Landrace $\times$ Large White and the mid-parent heterosis cross combination Large White $\times$ Meishan, Asian-Aust. J. Anim. Sci. 9 (2004) 1192-1196.

[13] Livak J.K., Schmittgen T.D., Analysis of relative gene expression data using real-time quantitative PCR and the $2^{-\Delta \Delta C T}$ method, Methods 25 (2001) 402-408.

[14] Moon Y.A., Lee J.J., Park S.W., Ahn Y.H., Kim K.S., The roles of sterol regulatory element-binding proteins in the transactivation of the rat ATP citratelyase promoter, J. Biol. Chem. 275 (2000) 30280-30286.

[15] Moon Y.A., Park S.W., Kim K.S., Characterization of cis-acting elements in the rat ATP citrate-lyase gene promoter, Exp. Mol. Med. 34 (2002) 60-68.

[16] Park S.W., Kim K.S., Whang S.K., Kim J.S., Kim Y.S., Induction of hepatic ATP-citrate lyase by insulin in diabetic rat - effects of insulin on the contents of enzyme and its mRNA in cytosol, and the transcriptional activity in nuclei, Yonsei Med. J. 35 (1994) 25-33.

[17] Ren Z.Q., Xiong Y.Z., Deng C.Y., Zuo B., Liu Y.G., Lei M.G., Age-dependent changes of differential gene expression profile in backfat tissue between hybrids and parents in pigs, Asian-Aust. J. Anim. Sci. 18 (2005) 682-685.

[18] Sato R., Okamoto A., Inoue J., Miyamoto W., Sakai Y., Emoto N., Shimano H., Maeda M., Transcriptional regulation of the ATP citrate-lyase gene by sterol regulatory element-binding proteins, J. Biol. Chem. 275 (2000) 12497-12502.

[19] Xu D.Q., Xiong Y.Z., Ling X.F., Lan J., Liu M., Deng C.Y., Jiang S.W., Lei M.G., Identification of a differential gene HUMMLC2B between F1 hybrids Landrace $\times$ Yorkshire and their female parents Yorkshire, Gene 352 (2005) 118-126. 